\title{
Towards adaptation of agriculture to climate change in the Mediterranean
}

\author{
Ana Iglesias - Raoudha Mougou - Marta Moneo • \\ Sonia Quiroga
}

Accepted: 11 November 2010/Published online: 1 December 2010

(C) The Author(s) 2010. This article is published with open access at Springerlink.com

\begin{abstract}
This study links climate change impacts to the development of adaptation strategies for agriculture on the Mediterranean region. Climate change is expected to intensify the existing risks, particularly in regions with current water scarcity, and create new opportunities for improving land and water management. These risks and opportunities are characterised and interpreted across Mediterranean areas by analysing water scarcity pressures and potential impacts on crop productivity over the next decades. The need to respond to these risks and opportunities is addressed by evaluating an adaptive capacity index that represents the ability of Mediterranean agriculture to respond to climate change. We propose an adaptive capacity index with three major components that characterise the economic capacity, human and civic resources, and agricultural innovation. These results aim to assist
\end{abstract}

\footnotetext{
A. Iglesias $(\square)$

Department of Agricultural Economics and Social Sciences, Avenida de la Complutense, sn, Universidad Politécnica de Madrid, 28040 Madrid, Spain

e-mail: ana.iglesias@upm.es

R. Mougou

Institut National de Recherche en Génie Rural, Eaux et Forêts (INRGREF), Ministry of Agriculture and Hydraulic Resources, Ariana, Tunisia
}

\section{Moneo}

Climate Impacts and Vulnerabilities,

Potsdam Institute for Climate Impact Research (PIK),

Potsdam, Germany

\section{S. Quiroga}

Department of Statistics,

Economic Structure and International Organisation,

Universidad de Alcalá, Alcalá de Henares, Spain stakeholders as they take up the adaptation challenge and develop measures to reduce the vulnerability of the sector to climate change.

Keywords Climate change - Adaptation - Agriculture · Water scarcity $\cdot$ Mediterranean

\section{Introduction}

Agriculture and water are closely interlinked in Mediterranean countries and shape the social development in many rural areas. Climatic conditions affect directly agriculture and water resources. Diseases and pest infestations over land and water are also weather-dependent. Societies, cultures, and economies have evolved adapting to mean climatic conditions. The success of adaptation depends on the strategy, and it is determined by the economic, social, and environmental vulnerability.

Agriculture is the main land use, user of water, and key activity for rural population over large areas in the Mediterranean. Water resources are essential to maintain a stable agricultural production, but also essential to supply to growing cities. In this region, it is likely that the stress imposed by climate change to agriculture is by means of reducing water availability (Iglesias et al. 2010b). Adaptation is a key factor that will shape the future severity of climate change impacts on food production (Lobell et al. 2008; Iglesias et al. 2010b). Prioritising adaptation needs is complex and, at least, requires information on: (1) water scarcity pressures, being water availability the main determinant of agriculture in the region; (2) a measure of the potential impacts; and (3) a measure of the potential limits (social and physical) to adaptation. Here, we evaluate these three aspects, 
discussing the adaptation priorities for agriculture in the Mediterranean region.

\section{Water scarcity pressures}

Mediterranean agriculture faces limited and variable rainfall and water availability. Irrigated agriculture is a small fraction of total agriculture, but it provides more than half of the food consumed, half value of the total agricultural earnings especially exports. Because water resources are limited, the use of water for irrigation competes with other uses of water, such as industrial, municipal, and water for ecosystems; this often results in social and environmental conflicts.

Rainfall and water resources are limited and difficult to predict from year to year. In many countries, demand largely exceeds the available water resources in most Mediterranean countries (Table 1). The potential water availability per capita and year considering the total freshwater resources in southern Mediterranean countries is less than $1,000 \mathrm{~m}^{3}$. Real available water resources are a small fraction of the total water resources in all cases. For example, in Spain, real available water resources are less than half of the total freshwater resources, and the potential use of surface water under natural regime is only $7 \%$ (Iglesias et al. 2007).

Water demand is raising due to demographic shifts, economic development, and lifestyle changes. Water use in the region is mainly for agriculture, accounting for more than $50 \%$ of total water use in all countries except France. Nevertheless, other economic and social water demands are rapidly increasing, such as tourism and ecosystem services (Iglesias et al. 2007). A commonly shared concern in the region is the ability to reach the targets of the Millennium Development Goals (MDGs), especially to halve by 2015 the proportion of people who do not have access to safe drinking water (Millennium Declaration, adopted by all members of the United Nations in September 2000).

The evolution of irrigation in all Mediterranean countries has been remarkable over the last half century, but northern and southern Mediterranean countries have varying rates of expansion of irrigated land and using different irrigation technologies. Irrigation technologies have increased water productivity up to 30 or $40 \%$ (Causapé et al. 2005; Luquet et al. 2005), and this has given a competitive advantage to many Mediterranean crops in European markets. Irrigation technologies ensure the best results when combined with efficient irrigation schedules or supplemental irrigation.

Intensive extraction of groundwater is a recent strategy to cope with the increasing water demand and has been undertaken in most Mediterranean countries. In most cases,

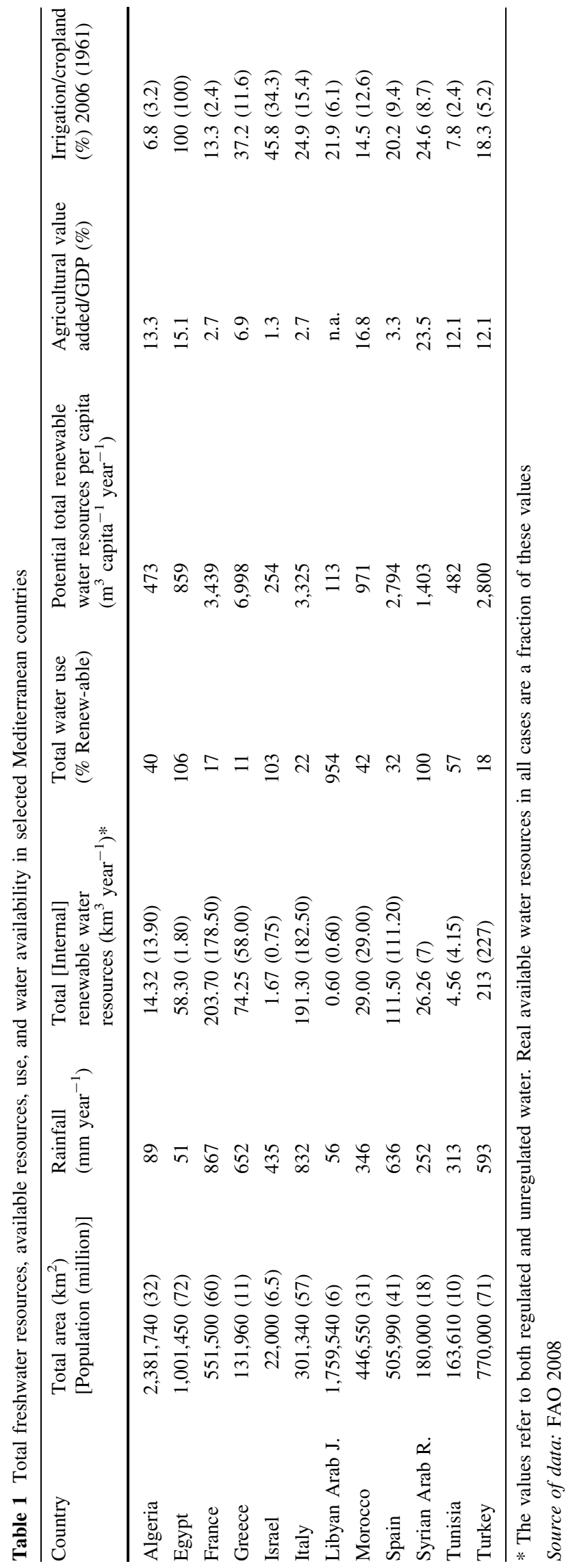


almost all groundwater extracted is used for irrigation (Garrido and Iglesias 2007; Fornes et al. 2005). The pressure on groundwater resources in the last decades partially arises from the rapid development of intensive irrigated agricultural areas but as well from an explicit growth of urbanisations. Groundwater resources play a vital role in meeting water demands, not only in terms of quality and quantity, but also in space and time, and are of critical importance for alleviating the effects of drought (Llamas 2000; Llamas and Martinez-Santos 2005). A common problem of aquifers in the Mediterranean region is the degradation of the groundwater quality due to multiple stresses: excessive pumping in relation to average natural recharge, return flow from irrigation water with intense use of agrochemicals, leakage from urban areas (land fills, septic tanks, sewers, mine tailings, among others, Barraque 1998; Fornes et al. 2005). In addition, drought episodes contribute in a significant way to the degradation of groundwater quality (Iglesias et al. 2007).

Many Mediterranean freshwater and groundwater resources are shared among countries taking the river Nile as an example. Within the countries, shared water among administrative units is also common. Disputes exist, especially during drought conditions, and potentially will increase due to the increasing water imbalances. Policies of a single government or water basin unit cannot resolve issues over shared water bodies, and local interests are likely to diverge. International institutions play a key role as formal mechanisms to deal with water-related conflicts in the region. Nevertheless, a common characteristic of the countries in the region is the weak cooperation among the different institutions related to agricultural and water management, and the fragmented roles of the country and its administrative regions that can result in conflicts (Iglesias et al. 2010a).

Wetland ecosystems depend to a significant degree on the sustainability of agro-ecosystems in Mediterranean countries (Llamas and Martinez-Santos 2005; Llamas 2000; Gerakis and Kalburtji 1998), and they have been seriously affected by irrigation schemes and individual farmers using groundwater resources. In some countries, habitats' conservation and agriculture are becoming irreconcilable interests (Hellegers et al. 2001).

\section{Potential impacts of climate change}

There are several hundred studies of the potential impacts of climate change on agriculture in the Mediterranean using many different approaches (Iglesias et al. 2000; 2010b; Quiroga and Iglesias 2009; El-Shaer et al. 1997). Studies focus on particular issues (e.g., soil erosion, biodiversity, and farm income), time-frames (e.g., 2020s, 2050s, and 2100), scenarios (e.g., SRES), and spatial scales (from local to regional). The results of the studies are diverse and sometimes contradictory due to different assumptions and approaches. Here, we outline the main potential impacts of climate change on Mediterranean agriculture. The impacts reported here have the following characteristics: (1) are highly certain (the majority of studies agree); (2) exacerbate the social vulnerability differences (and therefore social inequality); and (3) may be addressed by adaptation policy. This analysis aims to guide the selection of policies for adaptation.

\section{Climate and sea level rise projections}

Scientific projections of potential impacts of climate change on Mediterranean agriculture are uncertain and subject to numerous hypotheses. Climate change scenarios project higher than the global average increases in temperature, and changes in the hydrological cycle are expected in the region (IPCC 2007b; Giorgi and Lionello 2008). Climate change projections indicate a decrease in precipitation up to $-40 \%$, by the 2050 s compared to 1961-1990 levels in some areas, with changes in the annual precipitation patterns. In all cases, temperature increases of about $1.5^{\circ} \mathrm{C}$ are expected by the mid-2050s and thereby increased evaporation and reduced soil moisture, resulting in more adverse regional climate conditions than presently experienced. There is also a growing concern about the impacts of climate change on drought magnitude and frequency in the Mediterranean region (Giorgi and Lionello 2008) with severe implications for future water availability in the region (Iglesias 2009).

Increased sea level will affect agricultural production and water resources in the low-lying coastal areas, unless measures to protect vulnerable land or other land management schemes are put in place.

Changes in climate variability and extremes are likely to be at least as important as changes in mean climate conditions in determining climate change impacts and vulnerability (high confidence). Increased frequency of extremes events could result in higher insurance fees. The application of risk management techniques may contribute to increase the private coping capacity of farmers in these areas. But the ability of agricultural strategies to adapt to changes in climate and climate variability depends on the magnitude of such increase, the system being impacted and the adaptation options, as discussed below.

\section{Crop production}

Climate determines directly water availability and crop production. Iglesias et al. 2010a estimate the physical impacts of climate change on agricultural productivity by 
using a consistent and geographically explicit bottom-up methodology. Mediterranean crop yield changes were modelled under the HadCM3/HIRHAM A2 and B2 scenarios for the period 2071-2100 and for the ECHAM4/ RCA3 A2 scenario for the period 2011-2040. The yield changes include the direct positive effects of $\mathrm{CO}_{2}$ on the crops, the rainfed, and irrigated simulations in each geographic unit. Although each scenario projects different results, all scenarios considered are consistent in the spatial distribution of effects. Overall, crop productivity decreases are caused by shortening of the growing period, with subsequent negative effects on grain filling. It is very important to notice that the simulations consider no restrictions in water availability for irrigation due to changes in policy. In all cases, the simulations do not include restrictions in the application of nitrogen fertiliser. Therefore, the results of the Iglesias et al. 2010a study should be considered optimistic from the production point and pessimistic from the environmental point of view. The country and spatial data from the Iglesias et al. 2010a study are used here to derive uncertainty ranges for the Mediterranean region (Fig. 1).

In some regions of the Mediterranean, economic welfare of rural societies depends heavily on incomes generated by agriculture. Likewise, traditional farming systems are valued by some societies as a cultural heritage. Alternative income generator activities and employments in rural areas

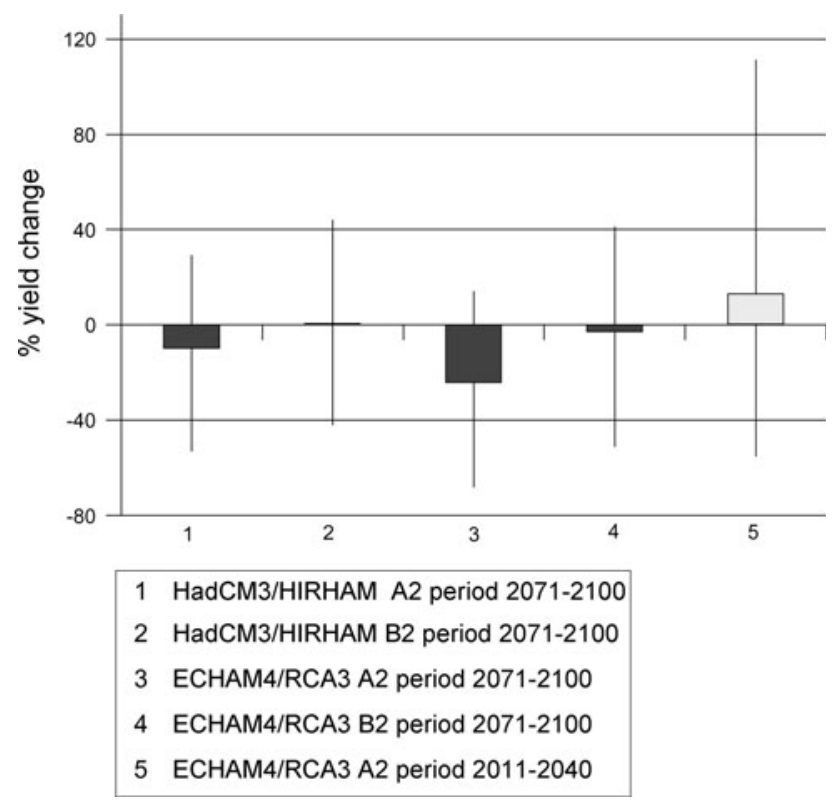

Fig. 1 Projections of production impacts in 2030 (2011-2040) and 2080 (2071-2100) expressed as percentage of 1970-2000 average yields under five climate scenarios. Boxes the range in average values in the Mediterranean countries; vertical lines indicate the standard deviation across the entire geographical area contribute to increase the private coping activity of farmers. Technology and innovation can also contribute to improve the competitiveness of farming systems. Despite these considerations, we have considered that farmer's private coping activity against the climate change impact is moderate.

Adaptation to these changes would require new investments and managerial skills. The financial feasibility of the new investments required will depend on the profits generated by the new optimal farming systems. The support of public agricultural education networks and agricultural research centres plays a key role for facilitating to farmers the acquisition of new managerial skills. For this impact, private coping capacity could be considered moderate. Decreases in productivity could cause agricultural use land abandonment. The level of confidence of these projections are estimated to be low because their uncertainty is the result of adding the uncertainty on future agricultural prices to the uncertainty upon the climate change impacts on agricultural productivity. The intensity of this impact could be considered high in the areas where the optimal farming systems are extensive. Intensive farming systems are more resilient to climate change.

An increasing number of studies are showing the effect of current climate variability and extremes in agricultural production, especially in areas where crops are cultivated near their climatic limits.

\section{Water availability}

All studies converge in the definite and significant impact of climate change on the further deterioration of water resources in the Mediterranean. The demand for water increases in all areas due to increases in crop evapotranspiration in response to increased temperatures. Increased water shortages, particularly in the spring and summer months, imply conflicts over water uses especially in southern countries (Döll 2002). Reduced water quality due to higher water temperatures and lower levels of runoff in some regions, particularly in summer, impose further environmental stress in irrigated areas. All this surely leads to increasing restrictions on irrigation in agriculture.

Private adaptation options to these impacts include agronomic practices such as conservation tillage or irrigation management (Olesen and Bindi 2002; Oweis and Hachum 2005). Increased competition for scarce water resources may promote the introduction of more efficient irrigation systems (Iglesias et al. 2009). However, private coping capacity can be considered moderate for this climate change impact because, in most areas, actions are highly dependent on the adaptation actions adopted by the hydrological sector, where public intervention continues to play a key role. Some authors have pointed out the need of 
reforming water markets to encourage a more prudent use of water (Iglesias et al. 2009).

Soil salinity and erosion

Soil degradation is a major threat to the sustainability of Mediterranean's land resources and may impair the ability of Mediterranean agriculture to adapt successfully to climate change. Mediterranean soils are currently experiencing a range of conservation problems, including high erosion rates (and erosion-derived agro-chemical pollution of waterways), declines in soil organic matter, and vulnerability of soil organic carbon pools. These are linked to site factors and changing land management practices and are being exacerbated by climate change and the increasing incidence of extreme weather events. Increased intensity of precipitation is likely to change patterns of erosion and accretion, increase the occurrence of storm flooding and storm damage and lead to greater incidences of waterlogging. The private adaptive capacity to this impact is considered low.

\section{Adaptive capacity}

Here, we use an adaptive capacity index to discuss the potential limits to adaptation. Water management and agriculture have shown throughout history a great ability to adapt to changing conditions, suggesting that the adaptive capacity is high. However, this ability varies with regions, activities and social groups. Here, we develop an index to estimate regional differences in adaptive capacity.

The evaluation of adaptive capacity has been previously addressed by several studies (Yohe and Tol 2002; Yohe et al. 2006; Ionescu et al. 2009). The issue of adaptive capacity is generally adopted as a modifier of the impact response functions, aiming to represent the capacity of a system to cope with or recover from a potentially damaging change in climate conditions. Previous studies by Yohe and Tol (2002) related to the evaluation of vulnerability or adaptive capacity to climate change, or the fourth assessment report from the IPCC (2007a) agree on the need to take several components into account in order to evaluate adaptation capacity.

Yohe and Tol (2002) and Ionescu et al. (2009) define eight determinants of adaptive capacity that include a variety of system-, sector-, and location-specific characteristics. These characteristics include socio-economic indicators, such as the availability of resources and their distribution among the population, the range of technological options and the stock of human capital. These eight determinants do not include climatic characteristics, but Yohe and Tol (2002) note that exposure to variability and extreme events is an important source of vulnerability. Furthermore, various definitions of adaptive capacity include biophysical indicators. Moss et al. (2000) define coping-adaptive capacity to include the components, such as economic capacity, human resources, and environmental capacity. Environmental capacity in their definition includes biophysical factors that influence coping capacity, such as $\mathrm{SO}_{x}$ emissions. In the current context, the definition of adaptive capacity given by the Parry ML (2007a) is applied: The ability of a system to adjust to climate change (including climate variability and extremes) to moderate potential damages, to take advantage of opportunities, or to cope with the consequences.

Yohe and Tol (2002) proposed a method for developing indicators for social and economic coping capacity in the context of climate change. Later, a simple index to quantify adaptive capacity was used by Ionescu et al. (2009) including only GDP, literacy rate, and labour participation rate of women. Yohe et al. (2006) used the VulnerabilityResilience Indicator Prototype (VRIP) developed by Brenkert and Malone (2005) as a proxy to adaptive capacity index. The capacity to adapt to environmental change is implicit in the concept of sustainable development and implies economic as well as natural resource components.

We propose an adaptive capacity index (AC index) with three major components that characterise the economic capacity, human and civic resources, and agricultural innovation. The scores of the $\mathrm{AC}$ index range on a scale of $0-100$, with the total being generated as the sum of each component. The approach is flexible and can be applied to managed and natural ecosystems as well as to socio-economic systems. The methodology is appropriate to integrate both quantitative and qualitative characterisations of adaptive capacity - this permits the involvement of the stakeholders in the process. The index can be applied locally or spatially and with different aggregation levels of the input data. The intermediate components can be evaluated independently, allowing comprehensive interpretation of the strengths and weaknesses of each system. A similar approach has been taken in the context of drought.

The sequential steps taken for the quantification of the adaptive capacity index are (1) Select proxy variables for factors that contribute to the adaptation capacity. (2) Normalise the proxy variables with respect to some common baseline. (3) Combine the sub-component proxy variables within each adaptive capacity category by weighted averages. (4) Quantify adaptive capacity as the weighted sum of the components. These four steps are applied to the baseline values and the SRES scenario values.

Table 2 shows the components of the $\mathrm{AC}$ index and proxy variables proposed for evaluating agricultural adaptive capacity to climate change. The variables 
Table 2 Components and proxy variables of the adaptive capacity index for the agriculture sector

\begin{tabular}{|c|c|}
\hline Components & Proxy variables \\
\hline Natural capacity & $\begin{array}{l}\text { Average precipitation } 61-90(\mathrm{~mm} / \mathrm{year}) \\
\text { Total water use (\% of renewable) } \\
\text { Agricultural water use }(\%) \\
\text { Area salinised by irrigation (ha) } \\
\text { Population density }\end{array}$ \\
\hline Economic capacity & $\begin{array}{l}\text { GDP millions US\$ } \\
\text { GDP per capita US\$ } \\
\text { Agricultural value added/GDP } \% \\
\text { Energy use (kg oil equivalent per capita) } \\
\text { Population below poverty line ( } \% \text { population with less that } 1 \mathrm{US} \$ \text { day) }\end{array}$ \\
\hline Human and civic resources & $\begin{array}{l}\text { Agricultural employment ( } \% \text { of total) } \\
\text { Adult literacy rate ( } \% \text { of total) } \\
\text { Life expectancy at birth (years) } \\
\text { Population without access to improved water ( } \% \text { of total) }\end{array}$ \\
\hline Agricultural innovation & $\begin{array}{l}\text { Irrigated area ( } \% \text { of cropland) } \\
\text { Irrigation technology ( } \% \text { drip irrigation) } \\
\text { Irrigation water use efficiency } \\
\text { Fertiliser consumption ( } 100 \mathrm{~g} / \text { ha of arable land) } \\
\text { Agricultural machinery (tractors per } 100 \mathrm{~km}^{2} \text { of arable land) }\end{array}$ \\
\hline
\end{tabular}

included were selected because (1) data were available and an example could be computed and (2) the variables are SRES scenario dependent and geographically explicit. Thus, each SRES storyline, time slice and country group are allocated an adaptive capacity class. The AC index may be used to understand the sensitivity of the system and assist in the selection of adaptation measures. Figure 2 summarises the results for the baseline and the A2 and B2 SRES scenarios.

The potential for improving water use efficiency is extremely large. The role of decision support systems available to the farmer is helping implementation of irrigation technology to evolve rapidly (Croke et al. 2002). Agricultural managers already use short-term weather forecasts in irrigation scheduling saving water with success, therefore, incorporating quantitative estimates of probabilistic climate conditions and modelling output into their decision-making process.

Technological development is also increasing the amount of available water by using non-conventional sources. For example, the recent availability of reuse and desalinisation technologies at market rates and wide scale continues to be developing at a fast rate, and the desalination capacity of Mediterranean countries has increased significantly (Abufayed and El-Ghuel 2001). Artificial local recharge of aquifers is considered as an effective technology in counteracting sea water encroachment and groundwater depletion. For example, artificial recharge in the Korba coastal aquifer of the tourist region of Cap Bon (Tunisia) has resulted in substantial decrease in the salinity

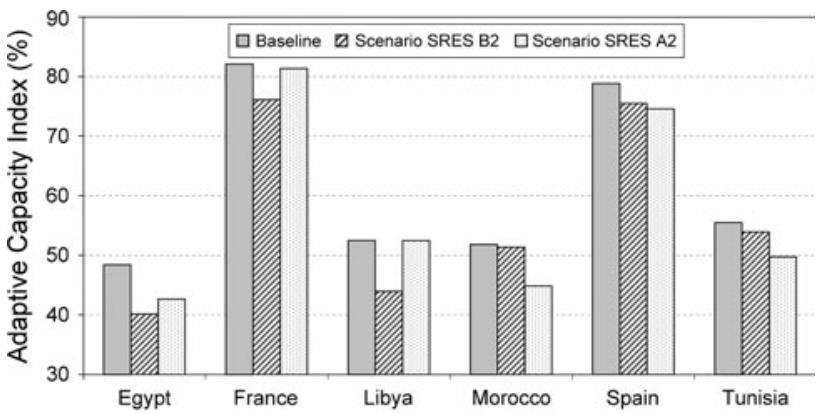

Fig. 2 Adaptive capacity index for the agriculture sector in selected Mediterranean countries (values range from 0 (lowest adaptive capacity) to 100 (highest adaptive capacity)

level in the central coastal portion of the aquifer (Paniconi et al. 2001).

\section{Conclusions}

Climate change will be a main determinant of future agriculture in the Mediterranean region, primarily by imposing further pressure on already scarce water resources. The changes in variability of agricultural productivity are larger than the changes in the mean under all climate scenarios considered. If projections become real, water scarcity in the Mediterranean is expected to rise in the next decades-posing additional problems to water management and water users. The combination of temperature 
increase and changes in the hydrological cycle limits some of the current adaptation measures, such as the increase in water for agricultural irrigation. This implies that the economic perspective for an expansion of, e.g., fruit and vegetable growing is limited. The human dimension of climate change impacts on the Mediterranean might not stop at the country level. There is the potential for more pronounced water conflicts of neighbouring countries, e.g., on shared rivers and aquifers.

Adaptation capacity in the Mediterranean region is a challenge as climate change comes in conjunction with high development pressure, increasing populations, water management that is already regulating most of available water resources, and agricultural systems that are often not adapted (any more) to local conditions. Evidence for limits to adaptation of socio-economic and agricultural systems in the Mediterranean region can be documented in recent history, and this is captured by the values of the adaptive capacity index. The values of the adaptive capacity index also capture the observed differences in the implementation of effective measures to cope with long-term drought and water scarcity in Mediterranean countries.

Potential adaptation options at the local level and regional level are extensive. For example, at the local level, adaptation initiatives may combine water efficiency initiatives, engineering, and structural improvements to water supply infrastructure, agriculture policies, and urban planning/management. At the national or regional level, priorities include, e.g., to place greater emphasis on integrated, cross-sectoral water resources management, using river basins as resource management units, and encouraging sound management practices. Given the increasing pressures on resources, and the considerable time and expense required to implement many adaptation measures, the agriculture and water resource sectors in many areas and countries will remain vulnerable to climate variability.

Acknowledgments We acknowledge the support of the AIACC AF90 project and the EU CIRCE project.

Open Access This article is distributed under the terms of the Creative Commons Attribution Noncommercial License which permits any noncommercial use, distribution, and reproduction in any medium, provided the original author(s) and source are credited.

\section{References}

Abufayed A, El-Ghuel MK (2001) Desalination processes application in Libya. Desalination 138(1):47-53

Barraque B (1998) Groundwater management in Europe: regulatory, organisational and institutional change. In: Hilding-Rydevik T, Johansson I (eds) How to cope with degrading groundwater quality in Europe. Stockholm, Sweden
Brenkert AL, Malone EL (2005) Modeling vulnerability and resilience to climate change: a case study of India and Indian states. Clim Change 72(1-2):57-102

Causapé J, Ouilez D, Aragüés R (2005) Groundwater quality in CR-V irrigation district (Bardenas I, Spain): alternative scenarios to reduce off-site salt and nitrate contamination. Agric Water Manage 84(3):281-289

Croke B, Cleridou N, Kolovos A, Vardavas I, Papamastorakis J (2002) Water resources in the desertification-threatened Messara Valley of Crete: estimation of the annual water budget using a rainfall-runoff model. Environ Model Softw Environ Data News $15: 387-402$

Döll P (2002) Impact of climate change and variability on irrigation requirements: a global perspective. Clim Change 54(3):269-293

El-Shaer HM, Rosenzweig C, Iglesias A, Eid MH, Hillel D (1997) Impact of climate change on possible scenarios for Egyptian agriculture in the future. Mitig Adapt Strat Glob Change 1(3):233-250

Fornes JM, De la Hera A, Llamas MR (2005) The silent revolution in groundwater intensive use and its influence in Spain. Water Policy 7:1-16

Garrido A, Iglesias A (2007) Groundwater's role in managing water scarcity in the Mediterranean Region. Paper presented at the the global importance of groundwater in the 21st century: international symposium on groundwater sustainability (ISGWAS), Alicante, 24-27 Jan 2007

Gerakis A, Kalburtji K (1998) Agricultural activities affecting the functions and values of RAMSAR wetland sites in Greece. Agric Ecosyst Environ 70(2-3):119-128

Giorgi F, Lionello P (2008) Climate change projections for the Mediterranean region. Glob Planet Change 63(2-3):90-104

Hellegers P, Zilberman D, van Ierland E (2001) Dynamics of agricultural groundwater extraction. Ecol Econ 37(2):303-311

Iglesias A, Rosenzweig C, Pereira D (2000) Agricultural impacts of climate change in Spain: developing tools for a spatial analysis. Global Environmental Change-Human and Policy Dimensions 10(1):69-80

Iglesias A, Garrote L, Flores F, Moneo M (2007) Challenges to manage the risk of water scarcity and climate change in the Mediterranean. Water Resour Manag 21(5):227-288

Iglesias A, Cancelliere A, Cubillo F, Garrote L, Wilhite DA (2009) Coping with drought risk in agriculture and water supply systems: drought management and policy development in the Mediterranean, vol 26. Advances in Natural and Technological Hazards Research. Springer, Dordrecht, The Netherlands

Iglesias A, Garrote L, Quiroga S, Moneo M (2010a) A regional comparison of the effects of climate change on agriculture in the European Union. Clim Chang (Submitted)

Iglesias A, Quiroga S, Moneo M, Garrote L (2010b) From climate change impacts to the development of adaptation strategies: challenges for agriculture in Europe. Clim Chang (Submitted)

Ionescu C, Klein RJT, Hinkel J, Klein R (2009) Towards a formal framework of vulnerability to climate change. Environ Model Assess 14:1-16

IPCC, 2007a: Climate Change 2007: Impacts, Adaptation and Vulnerability. Contribution of Working Group II to the Fourth Assessment Report of the Intergovernmental Panel on Climate Change, M.L. Parry, O.F. Canziani, J.P. Palutikof, P.J. van der Linden, C.E. Hanson, Eds., Cambridge University Press, Cambridge

IPCC, 2007b: Climate Change 2007: The Physical Science Basis. Contribution of Working Group I to the Fourth Assessment Report of the Intergovernmental Panel on Climate Change, S. Solomon, D. Qin, M. Manning, Z. Chen, M. Marquis, K.B. Averyt, M. Tignor, H.L. Miller Eds., Cambridge University Press, Cambridge 
Llamas MR (2000) Some lessons learned during the drought of 1991-1995 in Spain. In: Vogt JV, Somma F (eds) Drought and drought mitigation in Europe. Kluwer Academic Publishers, Dordrecht, The Netherlands, pp 253-264

Llamas MR, Martinez-Santos P (2005) Intensive groundwater use: silent revolution and potential source of social conflicts. J Water Resour Planning Manage 131(5):337-341

Lobell DB, Burke MB, Tebaldi C, Mastrandrea MD, Falcon WD, Naylor RL (2008) Prioritizing climate change adaptation needs for food security in 2030. Science 319(5863):607-610

Luquet D, Vidal A, Smith M, Dauzat J (2005) 'More crop per drop': how to make it acceptable for farmers? Agric Water Manage 76:108-119

Moss R, Brenkert AL, Malone EL (2000) Measuring vulnerability: a trial indicator set. Pacific Northwest national laboratory. Richland, WA, USA

Olesen JE, Bindi M (2002) Consequences of climate change for European agricultural productivity, land use and policy. Eur J Agron 16(4):239-262
Oweis T, Hachum A (2005) Water harvesting and supplemental irrigation for improved water productivity of dry farming systems in West Asia and North Africa. Agric Water Manage 80:57-73

Paniconi C, Khlaifi I, Lecca G, Giacomelli A, Tarhouni J (2001) A modelling study of seawater intrusion in the Korba Coastal Plain, Tunisia. Phys Chem Earth Part B-Hydrol Oceans Atmosphere 26(4):345-351

Quiroga S, Iglesias A (2009) A comparison of the climate risks of cereal, citrus, grapevine and olive production in Spain. Agric Syst 101:91-100

Yohe G, Tol RSJ (2002) Indicators for social and economic coping capacity-moving toward a working definition of adaptive capacity. Glob Environ Change 12(1):25-40

Yohe G, Malone EL, Brenkert AL, Schlesinger M, Meiji H (2006) Global distributions of vulnerability to climate. Int Assess $\mathbf{J}$ $6(3): 35-44$ 